\title{
CONSIDERAÇões SOBRE A CIVILIZAÇ̃̃o OCIDENTAL CONTEMPORÂNEA EM NiETzSCHE E Freud
}

\author{
Leonardo Carvalho Santos \\ Wilson Maranhão Sampaio ${ }^{\star \star}$
}

"Criar um animal que pode fazer promessas - não é esta a tarefa paradoxal que a natureza se impôs, com relação ao homem? Não é este o verdadeiro problema do homem?..."

Friedrich Nietzsche

\section{Resumo}

Este trabalho faz uma exposição das perspectivas de Nietzsche e Freud acerca da civilização ocidental contemporânea a partir dos escritos Genealogia da Moral, do primeiro, O Futuro de uma ilusão e O Mal-estar na Civilização do segundo. São discutidos aspectos referentes à vida na civilização, os mecanismos para lidar com o desprazer da vida em sociedade e os conflitos entre instinto [Trieb] e cultura. São apresentadas as perspectivas dos dois autores para revelar os elementos semelhantes, divergentes e complementares. Por fim, é discutida a importância destes dois autores para uma problematização da psicologia na condição de ciência humana.

Palavras-chave: civilização; ocidente; moral; instinto; culpa.

\section{CONSIDERATIONS ON WESTERN CIVILIZATION: FreUd AND NiETZSCHE AS A BENCHMARK}

"Creating an animal that can make promises - is not this the paradoxical task that nature has imposed in relation to man? This is not the real problem of man?..."

Friedrich Nietzsche

\begin{abstract}
This work is a presentation of the perspectives of Nietzsche and Freud on contemporary Western civilization from the writings Genealogy of Morals, the first, The Future of an Illusion and The Malaise Civilization in the second. Is discussed aspects related to life in civilization, the mechanisms to deal with

\footnotetext{
^ Psicólogo, graduado pela Universidade Salvador (UNIFACS).

E-mail: leonardocarvalho.psi@gmail.com do Curso de Psicologia da Universidade Salvador (UNIFACS).

E-mail:wmsampaio@gmail.com
}

$\star \star$ Psicólogo, Mestre em Educação pela Universidade Federal do Rio Grande do Sul, Coordenador
\end{abstract}


the unpleasantness of life in society and conflicts between instinct [Trieb] and culture. We present the perspectives of two authors to reveal the similar elements, different and complementary. Finally, we discuss the importance of these two authors for an analysis of the psychological condition of human science.

Keywords: civilization; west, moral, instinct, guilt.

\section{INTRODUÇÃo}

O presente trabalho visa demonstrar como se constituiu a civilização ocidental contemporânea como cultura, a partir das perspectivas de Friedrich Nietzsche e Sigmund Freud, tendo como alicerce as obras Genealogia da Moral (NIETZSCHE, 1998), O Futuro de uma Ilusão (FREUD, 1996[1927]) e O Malestar na Civilização (FREUD, 1996[1930]). A escolha por esses autores e seus respectivos textos se deve ao fato de possibilitar uma interface entre Filosofia e Psicologia - a partir desses pensadores de língua alemã - cujas trajetórias, por certo, contribuem para a formação de novos psicólogos.

O historiador e tradutor Paulo César de Souza (1998a) salienta no posfácio de Genealogia da Moral que seria proveitoso um estudo que buscasse aproximar as perspectivas trabalhadas por Nietzsche, nesta obra, com o texto freudiano $O$ Mal-estar na Civilização, pois há elementos que os tornam semelhantes. Entre estes elementos é possível destacar a forma pela qual ambos abordam o sentimento de culpa como parte da constituição subjetiva de cada sujeito, bem como fazem uso de recursos similares para lidar com o sentimento de desprazer na constituição da vida em sociedade.

Estas perspectivas aproximam a visão dos autores acerca do conflito entre instintos $[\text { Trieb }]^{1}$ e a cultura de cada povo ou nação com os mecanismos psicológicos envolvidos nesse contexto (NIETZSCHE, 1998). Por isso, propomo-nos realizar o desafio que Paulo Cesar de Souza lança para todos os leitores atentos de Nietzsche e Freud, na medida em que esta tarefa caracteriza-se como um recurso intelectual estimulante para a conclusão de uma graduação em Psicologia.

Nesta direção o presente escrito trabalhará o termo Civilização compreendendo este como foi proposto por Freud (1996[1930]), a saber, como sinônimo do conceito de Cultura. De acordo com Elias (1994) a terminologia Civilização abrange tudo o que a sociedade ocidental dos últimos dois ou três séculos descreve como sendo algo superior e que a constitui em lugar mais nobre quando comparada às sociedades mais antigas, incluindo a sua tecnologia, os seus costumes e o cultivo científico.

Essa palavra, porém, não tem o mesmo significado em todos os países do Ocidente. Para os alemães o termo Civilização denota algo útil, mas que só tem valor secundário e expressa a aparência externa, a superfície do ser humano, 
tendo sempre um cunho evolutivo, enquanto Cultura se refere aos fatos intelectuais, artísticos, religiosos e tende a fazer uma separação dos fatos políticos, econômicos e sociais (ELIAS, 1994).

Para Elias (1994) o conceito alemão de Cultura aponta para o processo histórico onde é possível refletir sobre a consciência de uma nação quando esta pode buscar e instituir, de modo incessante, as suas fronteiras, tanto no sentido político quanto espiritual, na medida em que esta nação fabrica a imagem que tem de si mesma. Portanto, esse conceito ressalta as invenções do espírito humano, enfatiza as diferenças nacionais e a identidade particular de grupos.

O termo civilização conforme Elias (1994) pode referir-se a uma grande variedade de fatos, incluindo as idéias religiosas, os costumes vigentes, dentre outros. Desta forma, empregaremos neste trabalho, também, o conceito de moral que, de acordo com Giacoia Junior (2006) se refere aos usos, costumes, normas de conduta, juízos de valor vigentes numa determinada sociedade. Acreditamos que este conceito envolve aspectos da civilização complementares àqueles abarcados pelo conceito de cultura e, com isso, permite alcançar uma compreensão mais ampliada do que tem abordado.

De acordo com Birman (2009) a categoria da palavra civilização, quando empregada por Freud nos seus escritos, se identificava com a do termo modernidade, com isso pode-se afirmar que a elucidação do mal-estar na civilização se referia ao mal-estar na modernidade. Este autor adverte ainda que não há um consenso entre os autores da atualidade sobre a definição do período histórico em que estamos vivendo e é possível identificar duas modalidades para se posicionar diante desse impasse: há aqueles que afirmam haver um fim da modernidade na atualidade, com a construção de um mundo pós-moderno, mas há também os que asseguram haver uma radicalização da modernidade, sem alteração dos seus pressupostos. Assim sendo, optamos pela segunda modalidade, pois também acreditamos que há uma perpetuação dos seus diversos pressupostos na forma como está constituída a civilização ocidental, tal como será explicitado, e utilizaremos o termo modernidade neste trabalho como sinônimo de contemporaneidade.

Birman (2009) nomeia como "modernismo" o movimento que visa efetuar uma crítica de diversos pressupostos da modernidade, como a crença na supremacia da razão e da consciência no psiquismo humano, proferida pelo cogito cartesiano "Penso, logo existo" (DESCARTES, 2009). Aquele autor considera Nietzsche, Marx e Freud como os grandes profetas desse movimento que estabeleceu uma ruptura com as premissas da modernidade. Sendo assim, o modernismo se configura como uma consciência crítica da modernidade, movimento no qual a psicanálise está situada devido à descoberta do inconsciente feita por Freud.

Conforme Birman (2009) Nietzsche, por sua vez, se faz presente no modernismo ao evidenciar a dimensão do poder no processo de produção da verdade, ao demonstrar como a mesma emerge a partir das relações de forças existentes entre os indivíduos e eliminando a suposição de que o eu e a razão são o fundamento dos mesmos. Nietzsche (1992) sinaliza que a moral vigente em uma determinada sociedade se configura a partir de relações de dominação sob as quais um sujeito nasce. 
De tal modo faremos uma articulação entre as perspectivas de Sigmund Freud e Friedrich Nietzsche sobre a modernidade e evidenciaremos ao leitor a importância do tema abordado para a prática profissional do psicólogo. Como salienta Nietzsche $(1998$, p. 7) "nosso tesouro está onde estão as colmeias do nosso conhecimento", portanto, acreditamos que este trabalho possibilita ampliar o nosso olhar sobre o ser humano no que se refere à sua vivência em sociedade.

\section{A PERSPECTIVA NIETZSCHEANA SOBRE A COMPOSIÇÃo DA MORAL OCIDENTAL MODERNA}

Nietzsche (1998) afirma que a motivação para desenvolver suas primeiras hipóteses sobre a origem dos valores morais se deve ao caráter improvável das teses inglesas sobre a procedência dos mesmos. $\mathrm{O}$ autor aponta que devido à influência do pensamento evolucionista de Charles Darwin os autores que teorizavam acerca da origem da moral, sobretudo ingleses, consideravam os valores morais vigentes naquela cultura além de qualquer questionamento, melhores do que quaisquer outros modos de valoração que tenham existido em épocas anteriores.

Segundo este autor os psicólogos ingleses desenvolviam teorias que estavam impregnadas de traços característicos da sua cultura, que servia de alicerce para a atribuição de valor, pois esses valores eram considerados uma conseqüência do aperfeiçoamento da humanidade, uma finalidade alcançada com o decorrer da história. Sendo assim, Nietzsche (1998) julgou que seria necessário investigar sob que condições e circunstâncias os valores vigentes foram inventados e até mesmo elaborar uma crítica acerca da sua importância. A forma considerada mais adequada pelo autor foi investigar através da história, efetuando uma pesquisa etimológica do significado de algumas palavras nas mais diversas línguas, de modo a identificar como os valores morais se estabeleceram.

Deste modo Nietzsche (1998) revela que a hegemonia política de uma classe social na antiguidade sempre implicava em um conceito de superioridade espiritual. O "bom" nas mais variadas línguas dos povos da antiguidade sempre significava o que era "nobre", "aristocrático" e se desdobrava em "espiritualmente privilegiado", opondo-se ao que era plebeu, comum, baixo - que significava "ruim". Esse modo de valoração foi chamado de juízos de valor cavalheirescoaristocráticos, que tinham como pressupostos uma condição física poderosa e aquilo que serve para conservá-los, como guerra, aventura, caça, dança, torneios e tudo que envolve uma atividade vigorosa, livre e alegre.

Nesta direção, se faz necessário distinguir duas morais, que travaram uma grande batalha ao longo da história - a moral dos senhores e a moral dos escravos (NIETZSCHE, 1998). A primeira correspondia aos juízos de valor cavalheirescoaristocráticos, pertencentes aos romanos, enquanto a segunda pertence aos judeus e surgiu a partir do cristianismo, que provocou um movimento contrário da segunda em relação à primeira - a rebelião escrava da moral. 
A moral dos escravos equivale ao que Nietzsche (1998) alcunha como juízos de valor nobre-sacerdotais, que privilegiam hábitos hostis à ação, como a busca pela paz, pois os judeus consideravam a guerra um mau negócio devido à sua impotência física. Este modo de valoração visa uma "elevação" moral e uma existência "superior" do ponto de vista espiritual, o que inclui o estabelecimento da igualdade de condições entre os indivíduos e a tentativa de dominação dos instintos humanos - o "ideal ascético". O judaísmo cristão compreende que a humanidade precisa de um propósito para a sua existência, que seria um modo de vida extinto de vontades singulares.

Assim sendo Nietzsche (1998) compreende que os propósitos do ideal ascético se sustentam numa fé metafísica, isto é, na crença de que há uma verdade em si - ofertada aos seres humanos por um deus e que foi alcançada pelo primeiro, como crente nesta fé - que deve ser seguida por todos. Essa crença é alimentada pela noção de livre-arbítrio, isto é, de que o homem é um sujeito autônomo, livre para agir independente dos seus instintos.

Nietzsche (1998) alega que a batalha moral ocorrida entre Roma e Judéia foi vencida pelos judeus e a moral moderna se configura como um desdobramento da moral decorrente daquele povo. A partir da disseminação desta moral pelo continente europeu foi assegurada a igualdade entre os indivíduos diante das leis e estabelecida a democracia como regime político em detrimento do regime aristocrático característico da antiguidade. Com o declínio da moral dos senhores se impôs na consciência humana a oposição egoísta e não-egoísta no seu modo de agir, sendo que as últimas passaram a ser enaltecidas devido à sua utilidade para a civilização, isto é, à possibilidade de ofertar a satisfação da maioria das pessoas, na tentativa de alcançar conforto, bem-estar e de assegurar a paz entre os sujeitos através da obediência às normas da civilização.

A partir desta perspectiva sobre a modernidade desenvolvida por Nietzsche (1998) pode-se compreender que a mesma não constitui um projeto civilizatório decorrente de uma linearidade da história humana, sobretudo o fruto da evolução do ser humano no tocante à constituição de um estilo de vida mais favorável à sua existência como pensavam os ingleses, mas o resultado do conflito entre dois estilos de vida diferenciados, vencido por um deles. Como conseqüência dessa vitória, seus costumes expandiram-se por grande parte do continente europeu e atravessou o Oceano Atlântico, chegando a América através da colonização que foi feita por diversos países europeus durante entre os séculos XVI e XIX. O motivo para a ocorrência do conflito entre as morais dos senhores e dos escravos pode ser atribuído ao conceito formulado por Nietzsche (1998) denominado "vontade de poder".

Nietzsche (1998) revela que a vida humana é composta por uma vontade de poder - forças agressivas, expansivas, geradoras de novas formas e interpretações presentes no ser humano - a qual pode explicar o desdobramento de todos os fenômenos históricos, psicológicos e culturais. Deste modo, segundo este autor, a moral moderna não pode ser compreendida como um acontecimento linear, mas a partir da ruptura estabelecida com o surgimento do cristia- 
nismo. A vontade de poder presente no judaísmo cristão criou uma nova forma de interpretação acerca do ser humano que se sobrepôs à moral dos senhores e produziu uma transformação nos costumes, normas de conduta e juízos de valor que se perpetuou ao longo da história.

Nesta direção Nietzsche (1998) aponta para a existência de um líder capaz de operar na consolidação e perpetuação deste modo de vida - o sacerdote ascético -, aquele que acredita nos ideais ascéticos e tem nestes a condição para exercer o seu poder na sociedade. Para isso dedica-se à busca de uma elevação espiritual e intelectual, de modo a servir de exemplo aos demais e funcionar como um pastor do rebanho de seres humanos na tentativa de forjar outro modo de operar por parte dos indivíduos de modo que estes vivam em condições consideradas mais favoráveis à sua existência, o que ocorre com a inibição dos seus instintos. Nietzsche (1998, p. 110) sinaliza que

O sacerdote ascético é a encarnação do desejo de ser outro, de ser-estar em outro lugar, é o mais alto grau desse desejo, sua verdadeira febre e paixão: mas precisamente o poder do seu desejo é o grilhão que o prende aqui; precisamente por isso ele se torna o instrumento que deve trabalhar para a criação de condições mais propícias para o ser-aqui e o ser-homem.

Nietzsche (1998) salienta que a ciência é a maior aliada do ideal ascético, pois o saber científico é um instrumento de poder do sacerdote ascético com a finalidade de disciplinar o indivíduo. Podemos supor que as ciências, sobretudo as humanas e da saúde, cumprem esse papel de forma significativa. Esse disciplinamento ocorre por meio da sua conscientização, para que este se enquadre nos princípios dos ideais ascéticos. $\mathrm{O}$ direito e a psiquiatria se configuram como duas ciências bastante importantes nesse processo, pois a primeira estabelece as leis que regulam o agir humano, tendo naqueles pressupostos o seu alicerce, e a segunda emprega classificações para as condutas que estejam fora do padrão idealizado - compreendendo-as como patológicas - e utilizam as drogas para tentar dominar os corpos.

Para a consolidação deste modo de vida é fundamental a formação de uma consciência no ser humano, para que este obedeça às regras vigentes na civilização. Por isso, são empregadas diversas medidas coercitivas, como assinala Nietzsche $(1998$, p. 50) que afirma ser uma máxima da psicologia, o fato de que "grava-se algo a fogo, para que fique na memória". O castigo então é aplicado como forma de punir alguém que violou as normas vigentes - um inimigo da paz, da ordem social e da autoridade - na tentativa de alcançar um estado absoluto de negação da expressão das forças agressivas presente no homem, tornando-o um animal manso.

Devido lembrança de imagens referentes a diversos tipos de castigo aplicados ao longo da história humana retém-se na memória uma série de atitudes consideradas inadequadas à vida na civilização e se faz uma promessa para viver os benefícios que a mesma lhe oferece e, com a ajuda dessa qualidade de memória chega-se finalmente à razão (NIETZSCHE, 1998). O agir 
racional do ser humano, portanto, não é algo inato, mas que se constituiu ao longo da sua história em decorrência de uma série de castigos aplicados com o intuito de lhe fixar um modo de operar.

Neste sentido foi consolidado um dispositivo jurídico na civilização ocidental que está baseado nos princípios do ideal ascético derivados do cristianismo e sustentado na forma de relação entre credor e devedor, já que esta ocorre entre os indivíduos desde os primórdios da existência humana, empregada nas formas mais básicas de comércio que ocorriam antes mesmo de haver qualquer tipo de organização social, sendo reguladas por um contrato (NIETZSCHE, 1998). O poder judiciário herdou desse tipo de relação o princípio de que tudo pode ser pago, isto é, de que há uma equivalência entre qualquer infração cometida por um indivíduo e o malefício causado. Com isso, o sujeito causador do dano tem necessidade de cumprir algo para pagar a sua dívida, o que ocorre por meio de um castigo aplicado contra o mesmo (NIETZSCHE, 1998).

A civilização, portanto, está organizada sob esta base, a da relação entre credor e devedor, já que, supostamente oferece segurança e paz aos indivíduos com a aplicação de uma série de mecanismos de coerção com o objetivo de sustentar tais benefícios que oferece. Com isso, a civilização está situada na condição de credora, merecedora de reconhecimento e retribuição, enquanto o indivíduo que infringe alguma norma está no papel de alguém que necessita cumprir algo em retribuição ao que lhe foi concedido - o devedor. Com as medidas de coerção impostas pela civilização o homem é tornado consciente da responsabilidade de retribuir à civilização os benefícios que esta o oferece. Nietzsche (1998, p. 50) pontua que:

O orgulhoso conhecimento do privilégio extraordinário da responsabilidade, a consciência dessa rara liberdade, desse poder sobre si mesmo e o destino, desceu nele até sua mais íntima profundeza e tornou-se instinto, instinto dominante como chamará ele a esse instinto dominante, supondo que necessite de uma palavra para ele? Mas não há dúvida: este homem soberano o chama de sua consciência [...].

Da relação entre credor e devedor se origina o sentimento de culpa no ser humano, pois devido à imposição da paz e da obediência às leis como valores a ser seguidos por todos na civilização o homem aprende a se envergonhar dos seus próprios instintos, que são amorais. Nietzsche (1998) sinaliza que o homem é dotado de um instinto de agressividade e este apenas mudou de direção na modernidade, deixando de descarregar para fora e passando a voltar contra si mesmo, na tentativa de inibir a sua expressão. Isso constitui o caráter paradoxal do ideal ascético, a tentativa de voltar um instinto vital contra a sua própria expressão, na tentativa de controlar aquilo que há de vida mesma e inibir a sua manifestação. Logo, da internalização do instinto de agressividade, que se volta para dentro de si mesmo, é que advém a consciência ou "má consciência", no ser humano. 
Nietzsche (1998) destaca que o sacerdote ascético faz indicações para o homem moderno lidar com o desprazer gerado pela vida na civilização, que se dá pelo processo de inibição do seu instinto de agressividade. Essas indicações são a religião, o entorpecimento e o trabalho. Esses mecanismos, porém, não combatem a causa da dor, mas somente a sensação de desprazer.

A religião funciona como um narcotizante, isto é, através desta tenta-se fugir das dores da vida através da sua desvalorização, da busca por cumprir os preceitos religiosos com o intuito de assegurar uma vida plena de satisfação após a morte - no caso do cristianismo. O entorpecimento funciona como forma de reduzir ao máximo o funcionamento da atividade nervosa, o que pode ocorrer através da utilização de diversas outras drogas ilícitas e lícitas como os remédios psiquiátricos. O trabalho - a atividade maquinal - como Nietzsche (1998) o alcunha, serve como forma de ocupar a consciência do homem a todo o momento com uma série de atividades para preencher o seu tempo já que a mesma, conforme este autor, é pequena para abrigar muitos conteúdos.

\section{A PERSPECTIVA FREUDIANA ACERCA DA CIVILIZAÇÃO OCIDENTAL}

Na sua formulação sobre a constituição da civilização Freud (1996[1927]) revela supor que esta se constituiu através da imposição de uma minoria de indivíduos que, dotada de meios para exercer poder e coerção sobre os demais, passou a dominar uma população em maior número. A coerção e a imposição da renúncia às pulsões seriam premissas para a existência da civilização, pois há no ser humano tendências anti-sociais e destrutivas que são fortes o suficiente para determinar em algumas pessoas a sua conduta na sociedade. Para este autor todo indivíduo é potencialmente inimigo da civilização devido às renúncias pulsionais que esta lhe impõe através dos mecanismos de coerção e por conta das tendências anti-sociais presentes no próprio, embora se acredite que aquela seja um interesse de todos os seres humanos.

A civilização, segundo Freud (1996[1927]), tem como objetivos controlar as forças da natureza e extrair a riqueza suficiente para satisfazer as necessidades dos indivíduos, além de estabelecer regras para ajustar as relações entre os mesmos e a distribuição da riqueza disponível. Este autor considera importante que a sociedade seja regulada por uma minoria que saiba dominar suas pulsões, de modo a fazer a renúncia da qual a existência depende e sejam reconhecidos como líderes, como exemplos a serem seguidos por toda a população. A utilização dos mecanismos de coerção se deve ao fato de o ser humano não possuir afinidade com o trabalho, algo necessário a toda civilização, e à hegemonia das pulsões sobre a razão, pois os argumentos não têm valor algum diante das forças pulsionais.

De modo a compreender da forma mais ampla possível o funcionamento da mente humana Freud formulou ao longo dos seus estudos duas concepções sobre o aparelho psíquico, conhecidas como primeira e segunda tópicas. Na primeira Freud (1915b) afirmou que o eu ${ }^{2}$ humano é dividido em três instâncias: consciente, pré-consciente e inconsciente - sendo que a primeira é apenas a parte superficial do nosso aparelho, a instância mental que envolve todos os conteúdos 
perceptíveis, tudo aquilo que é conhecido. O pré-consciente serve de intermediário entre o inconsciente e a consciência, pois abrange os conteúdos que não estão presentes no campo atual da consciência e, portanto, são inconscientes no sentido descritivo do termo, mas diferenciam-se dos conteúdos do sistema inconsciente na medida em que permanecem acessíveis à consciência. Na terceira instância - $\mathrm{o}$ inconsciente - se localizam as pulsões e as representações psíquicas recalcadas ou aquelas que nunca poderão chegar à consciência.

Na segunda tópica, Freud (1996[1923]) assinala que há outras três instâncias no psiquismo humano, que são o isso, o eu e o supereu. A primeira corresponde ao depósito inicial da energia psíquica e os seus conteúdos correspondem à expressão psíquica das pulsões, localizadas no inconsciente. Essa instância entra em conflito com o eu, que se encontra dividido nas outras três instâncias - consciente, pré-consciente e inconsciente - sendo que é em grande parte inconsciente, item que corresponde à maior parte do aparelho psíquico. $\mathrm{O}$ eu pode ser concebido como um pólo de defesa ou de adaptação à realidade e está numa relação de dependência em relação às reivindicações do isso, aos imperativos do supereu e às exigências da realidade. A terceira instância - o supereu - tem como função fazer um julgamento moral das ações e dos desejos humanos, exercer uma autoobservação constante e funcionar como uma força de coerção internalizada por parte do próprio homem na sua consciência (FREUD, 1996[1927]).

O supereu, conforme Freud (1996[1927]), constitui uma vantagem cultural no âmbito psicológico. Para este autor a maioria das pessoas obedece às normas de conduta estabelecidas pela civilização devido ao temor que há em relação à coerção externa, portanto, a internalização da coerção constitui uma vantagem, pois desta forma o indivíduo se torna um sujeito moral e social.

Nesta direção, Freud (1996[1930]) assegura que o indivíduo - hostil à civilização - encontra diversas formas para tentar combater a sua hostilidade em relação à própria, pois o ser humano visa, além de obter prazer, eliminar as sensações de desprazer que lhe ocorre. A forma mais rude para tentar evitar a sensação de desprazer está o uso de substâncias químicas, mas há outras maneiras, como a tentativa de aniquilar as pulsões - que é muito comum em diversas religiões - como no cristianismo, propiciando uma desvalorização do que há de vida nos sujeitos. Há também a utilização do mecanismo de sublimação, que é o direcionamento das pulsões para a realização de trabalho psíquico e intelectual ou outras atividades socialmente valorizadas, desempenhando um papel fundamental no desenvolvimento cultural, como as atividades artísticas o cultivo científico.

A religião, conforme Freud (1996[1927]) é possivelmente o registro psíquico mais importante da civilização, o que de mais precioso pode ser oferecido por esta. $\mathrm{O}$ anseio do homem por deuses se deve ao seu sentimento de desamparo em relação à força esmagadora da natureza, que não pode ser inteiramente controlada pela civilização. Assim sendo, os deuses têm a missão de exorcizar os perigos da natureza, harmonizar o homem com a crueldade do destino - sobretudo a morte - e consolá-los pelos sofrimentos e privações que a sociedade lhe impõe. 
Devido à necessidade do homem de tolerar o seu desamparo foram criadas diversas idéias, como a premissa de que a vida no mundo serve a um propósito mais elevado. Esse propósito seria o aperfeiçoamento da natureza do homem, da sua parte espiritual - desprendida do corpo - que seria o objeto desta elevação. Com as restrições pulsionais estabelecidas pela civilização - como o canibalismo, o incesto e a ânsia de matar -, consideradas pré-condição para a sua existência, o homem se separa da sua condição animal, isto é, da possibilidade de agir livremente de acordo com a sua condição biológica - o que seria esse suposto aperfeiçoamento da sua natureza (FREUD, 1996[1927]).

As doutrinas religiosas encontram a sua força interior na realização dos desejos mais antigos da humanidade, sendo ilusões provenientes dos desejos humanos e correspondendo à realização destes. Freud (1996[1927]) as considera ilusões devido ao fato de desprezarem suas relações com a realidade, não por serem necessariamente falsas.

O escrito de Freud (1996[1927]) demonstra que a civilização ocidental está baseada em muitas premissas decorrentes do cristianismo e, caso as pessoas deixem de acreditar em tais verdades, se sentirão isentas da obrigação de cumprir as normas da civilização. Isso representa uma ameaça à sua manutenção devido às pulsões anti-sociais e egoístas dos homens, que lutarão para exercer seu poder sobre os demais, instaurando uma grande desordem. Contudo, Freud (1996[1927]) aponta para o que seria uma grande vantagem: admitir que todas as regulamentações presentes na civilização provém de uma criação humana e não de um deus que ofertou uma verdade absoluta e imutável. Este autor acredita que as normas perderiam sua rigidez e poderiam ser modificadas quando necessário, fazendo com que as pessoas compreendam que aquelas têm o papel de servir aos seus interesses e não somente exercer uma dominação sobre elas, possibilitando uma relação menos hostil para com as leis.

No tocante aos benefícios da religião cristã, Freud (1996[1927]) pontua que a mesma contribuiu para o homem conseguir dominar as suas pulsões antisociais, mas não torna feliz a maioria da humanidade, gera apenas a insatisfação e a infelicidade da maioria das pessoas em relação à civilização, pois a sentem como uma coisa da qual precisam se libertar. Entretanto a sua influência tem diminuído significativamente devido ao cultivo científico e à expansão desse tipo de conhecimento, porque quanto mais os homens têm acesso à ciência maior o afastamento da crença religiosa, até mesmo nos seus princípios essenciais. Ao revelar motivos racionais para os fatos da vida que muitas vezes contestam os dogmas religiosos, a ciência propiciou um declínio do cristianismo.

Freud (1996[1930]) salienta que os instintos anti-sociais e a inclinação para a agressão, presentes no homem, constituem no próprio uma característica instintiva original, que representa a maior barreira à civilização. Desta maneira a civilização ocidental prioriza uma forma de subjetivação masoquista, isto é, privilegia o direcionamento da pulsão de agressividade do homem para dentro de si mesmo, como forma de evitar a sua descarga, em oposição ao sadismo, no qual o sujeito direciona a agressividade para fora. Para que o indivíduo se torne inofensivo o seu 
desejo de agressão é inibido e sua agressividade é internalizada formando o supereu, fato que pode causar tanta infelicidade para o sujeito que a inibe quanto a que seria gerada àquele em quem a agressividade seria descarregada.

As ações agressivas do homem, consideradas "más", freqüentemente não são prejudiciais ao eu, pode ser exatamente o oposto - algo prazeroso -, todavia, o supereu é que irá julgar se as ações são boas ou más. O desejo de executar uma ação que não esteja de acordo com os costumes da civilização gera a 'má consciência', isto é, o sentimento de culpa simplesmente por ter desejado praticá-la. Não é necessário executar tal ação, pois nada pode ser escondido do supereu - a coerção internalizada - que vigia o homem constantemente. Freud (1996[1930]) alerta que o sentimento de culpa do homem advém de duas origens: do medo da autoridade e do medo do supereu, isto é, da punição que o homem pode sofrer dos dispositivos de coerção presentes na sociedade ou da relação que a sua consciência moral tem com o cumprimento das leis vigentes.

A consciência, portanto, corresponde ao resultado da renúncia pulsional, sendo que, posteriormente, a relação se inverte e o fato de estar consciente faz com que o sujeito renuncie à expressão de algumas pulsões. A consciência do homem, por conseguinte, surge devido ao recalque ${ }^{3}$ das suas pulsões agressivas e, em seguida, novas inibições dos mesmos tipos voltam a ocorrer (FREUD, 1996[1930]).

\section{AS PERSPECTIVAS DE NIETZSCHE E FREUd SOBRE A CONTEMPORANEIDADE}

Friedrich Nietzsche e Sigmund Freud têm obras que trazem grandes contribuições para a compreensão do período histórico em que estamos vivendo, como já foi afirmado no começo deste trabalho, e seus pontos de vista destacam elementos comuns nas críticas que empregam à modernidade. Suas concepções enfatizam elementos como o sentimento de culpa presente no homem moderno, as estratégias para lidar com o desprazer da vida em civilização e, sobretudo, os conflitos presentes no homem no tocante aos instintos e a cultura. É possível constatar como os seus trabalhos permanecem bastante atuais na compreensão da contemporaneidade.

Embora Freud seja reconhecido como descobridor do inconsciente na mente humana, conforme Giacoia Junior (2004), Nietzsche já havia desconstruído a suposta primazia da consciência no psiquismo humano, além de ter reconhecido e valorizado a existência de um amplo psiquismo inconsciente. Este autor ressalta que Nietzsche propôs uma nova forma de compreender os processos de subjetivação, que se dirige a uma concepção alargada do corpo e da racionalidade, incluindo a tarefa de reportar o campo espiritual da cultura aos fatores afetivos e instintuais que a condicionam - o que ratifica a semelhança em alguns aspectos dos escritos destes autores.

Em contrapartida, Naffah Neto (1997) alega que as relações históricas entre Nietzsche e Freud continuam controvertidas, pois ainda que os escritos destes autores sejam rigorosamente consecutivos, no sentido cronológico do termo, há divergências entre os psicanalistas acerca do possível acesso do segundo as obras do primeiro. Devido à semelhança em diversos aspetos do pensamento desses 
dois autores Naffah Neto (1997) ressalta que "poderíamos chegar a supor que Freud teria sido um mero continuador das idéias nietzscheanas, ${ }^{4}$ desdobrando-as e dando-lhes um cunho terapêutico" (p. 42) se seguirmos esta direção. Entretanto, podemos constatar também algumas diferenças significativas no que se refere ao modo como estes autores avaliam a cultura ocidental e na maneira como explicam fenômenos comuns às suas obras.

Uma semelhança pode ser identificada no fato de que ambos os autores atestam a importância do cristianismo para a consolidação da modernidade, reconhecendo que a segunda está sustentada em princípios derivados daquela doutrina. Porém, estes autores divergem quanto ao juízo atribuído à modernidade, pois Freud (1996[1927]) reconhece o modo de vida desse período histórico como uma evolução humana, enquanto Nietzsche (1998) a considera um sintoma de decadência do ser humano devido às repressões instintuais que lhe são impostas por conta de valores tidos como mais importantes do que sua condição animal do homem.

Freud (1996[1927]), entretanto, critica a rigidez dos valores cristãos que se perpetuaram e considera que seria importante atribuir ao ser humano a origem de todas as regulamentações estabelecidas na civilização, para propiciar uma melhora nessa relação e promover a felicidade da maioria das pessoas. Este autor tem uma percepção evolucionista acerca da civilização ocidental, pois considera a tentativa de estabelecer uma segurança nas relações entre os indivíduos - muito mais próxima de ser alcançada na modernidade - um fator decisivo nessa análise. Por isso defende que a renúncia à expressão das pulsões de agressividade do ser humano constitui uma grande vantagem da civilização e ressalta que uma ordem jurídica universal soberana seria bastante valiosa para o ser humano.

Na sua concepção sobre a cultura ocidental Nietzsche (1998), contudo, assinala que a coerção e a renúncia aos instintos não são pré-condição para a constituição de uma cultura, pelo contrário, esta deve exaltar o ser humano - não na perspectiva judaico-cristã que prioriza uma elevação espiritual - mas no que se refere à expressão dos seus instintos. Os instrumentos de coerção existentes na civilização com o objetivo de disciplinar o homem, conforme o mesmo autor são apenas conseqüência da vitória dos ideais provenientes da moral dos judeus sobre a moral dos romanos e a modernidade representa um retrocesso da humanidade.

Desta forma, Nietzsche (1998, p. 34) ressalta que "esses 'instrumentos da cultura' são uma vergonha para o homem, e na verdade uma acusação, um argumento contrário à cultura", com isso ressalta que a busca pelo bem-estar de todos, bem como o modo de agir não-egoísta em detrimento da satisfação pessoal, constitui uma vontade de se maltratar - uma enfermidade psicológica dos indivíduos modernos. Este autor, de forma oposta a Freud (1996[1930]) assinala que:

Uma ordem de direito concebida como geral e soberana, não como meio na luta entre complexos de poder, mas como meio contra toda luta, mais ou menos segundo o clichê comunista de Dühring, de que toda vontade deve considerar toda outra vontade como igual, seria um princípio hostil à vida, uma ordem destruidora e desagregadora do homem, 
um atentado ao futuro do homem, um sinal de cansaço, um caminho sinuoso para o nada. (NIETZSCHE, 1998, p. 65, grifo do autor).

Nietzsche (1992) destaca o fato de que em toda formulação teórica existem afetos envolvidos, o ser humano não consegue se distanciar das suas sensações, de tudo que há vida em si mesmo e em todo pensador é a sua vontade de poder que cria ideais com o objetivo de que estes sejam seguidos por todos. Por isso, constitui um erro acreditar que pode existir uma verdade absoluta alcançada apenas por meio do uso da razão e que todos os seres humanos possam se identificar com a mesma, pois apenas existem perspectivas formuladas por um sujeito dotado se afetos singulares. Considerando a vontade de poder como um componente da vida pode-se compreender que viver com base em leis formuladas por outrem corresponde a algo hostil à vida, pois cada indivíduo deve viver de acordo com as suas próprias leis, imprimindo a forma de que deseja viver.

No nosso entendimento, Freud (1996[1930]) e Nietzsche (1998) estão de acordo com o fato de que o homem da antiguidade experimentava uma satisfação instintual muito mais prazerosa do que o homem moderno, pois Freud (1996[1930]) revelou que este homem da modernidade trocou uma parcela do seu prazer pela segurança da vida em civilização. Nietzsche (1998), contudo, critica a busca do homem moderno por segurança e bem-estar, pois compreende que a tentativa de evitar a dor corresponde a um empobrecimento da vida, que ocorre com as renúncias instintuais praticadas nesse período, em decorrência da moral cristã que influencia significativamente o valor atribuído a essas intenções.

No que se refere ao surgimento da religiosidade os autores fornecem perspectivas que têm elementos comuns, como o fato de atribuírem a origem de Deus a um ancestral da linhagem primitiva mais poderosa de uma comunidade, pois há uma fantasia que esta sobrevive somente devido aos sacrifícios feitos pelos antepassados, sobretudo do primeiro, e como conseqüência dessa fantasia, o ancestral é transfigurado em Deus. Todavia os autores fornecem explicações diferentes para o surgimento do cristianismo.

Freud (1996[1927]) adota um esclarecimento descontextualizado da sua gênese, privilegiando o elemento intrapsíquico do desamparo, o qual poderia explicar o anseio do homem por deuses em qualquer cultura, assim como as características provenientes da moral cristã. O sentimento de desamparo poderia explicar as especificidades do cristianismo em relação à sua moral, o que inclui o desejo de ver extinto os terrores da natureza, a procura por um consolo para morte e a busca de recompensas pelas privações da vida civilizada - fatores intrínsecos ao cristianismo.

Enquanto isso Nietzsche (1998) atribui a origem da moral cristã a outro componente psíquico, contudo, relacionado ao contexto do seu surgimento: o ressentimento dos judeus em relação aos valores nobres dos romanos. O ressentimento, tal como compreende este autor, corresponde ao estado de rancor e desejo de vingança 
no qual o ressentido é incapaz de criar valores de modo espontâneo e afirmativo, de tomar a si mesmo como fonte criativa. Os judeus, portanto, necessitaram dos romanos para, a partir do rancor em relação aos últimos, construir sua própria identidade.

Pode-se então identificar uma complementaridade entre o conceito de ressentimento formulado por Nietzsche (1998) e a forma de subjetivação masoquista característica da modernidade atestada por Freud (1996[1930]), pois a segunda é conseqüência do primeiro. $\mathrm{O}$ ressentido inibe a manifestação dos seus instintos agressivos devido à sua impotência diante dos mais fortes, fenômeno que se proliferou na modernidade devido às medidas de coerção empregadas pelo Estado, responsáveis pela formação do supereu no indivíduo.

Nietzsche (1998) aponta que, diferente da relação que os judeus e os indivíduos modernos têm com Deus, os gregos da antiguidade se relacionavam de forma bastante distinta da que ocorre com os primeiros, pois os deuses gregos serviam para divinizar o ser humano - exaltar a sua condição animal -, afastar a má consciência ou sentimento de culpa de si, para que eles continuassem gozando da sua liberdade. Eles se relacionavam com a culpa de maneira inversa ao cristianismo, já que o homem culpava os deuses pelas suas ações maléficas, em vez de culparem a si mesmos. Os deuses gregos, com isso, amparavam o homem até mesmo nas suas ações trágicas (NIETZSCHE, 1998).

Assim sendo, a relação dos gregos da antiguidade com a culpa era bastante diferente da que ocorre com o indivíduo moderno. Os primeiros não se sentiam culpados, pois ainda que tivessem cometido um determinado ato a responsabilidade poderia ser deslocada de si. Naffah Neto (1996) revela que no período de transição da era aristocrática para a democrática no Grécia antiga a noção de responsabilidade não era totalmente constituída, pois os gregos acreditavam que os deuses podiam se apoderar do corpo de um indivíduo e enlouquecê-lo, fazendo com que este cometa os atos mais insensatos, incluindo roubos, assassinatos e outros crimes. Com isso, um sujeito não poderia ser considerado responsável pelos atos cometidos se estes tivessem acontecido em decorrência do poder de algum deus. Embora não se acreditasse na existência de um psiquismo inconsciente é possível perceber que os gregos reconheciam a impossibilidade de dominar completamente as forças presentes em si mesmo, direcionar todas as suas ações, pois reconheciam que havia algo que os determinava e escapava do controle da racionalidade.

No sentido oposto a esse, o homem moderno é acometido pelo sentimento de culpa a partir de duas origens, como salienta Freud (1996[1930]), o medo do supereu - como já foi explicitado - e das autoridades instituídas. Esta última origem está sustentada nos diversos poderes disciplinares da civilização que visam enquadrar os indivíduos - instituições pedagógicas como a escola, psicológicas ou psiquiátricas como o hospital, o asilo, a polícia, dentre outros -, surgidos a partir do final do século XVIII e início do século XIX, período em que se ínicia o que pode ser chamado de sociedade disciplinar, conforme Foucault (2005). 
Em conseqüência dos pressupostos do ideal ascético, que visam eliminar a expressão de todas as forças espontâneas e agressivas, o homem moderno utiliza outro meio para fugir do desamparo na vida em civilização - o pacto masoquista. Birman (2009, p. 26) acrescenta que

O masoquismo seria a forma privilegiada de ser da subjetividade, que se protege dessa maneira triste de um suposto malefício maior produzido pela modernidade, qual seja, o desamparo. Vale dizer que para se protegerem do horror do desamparo, as individualidades se valem do masoquismo como forma primordial de subjetivação.

Tal forma de subjetivação está de acordo com a premissa sustentada por Nietzsche (1998) de que o homem moderno busca um sentido para o seu sofrimento, sentido este que está na busca por segurança e paz entre os indivíduos na vida em civilização, que seria conseqüência do suposto aperfeiçoamento da sua natureza. Contudo, a busca do homem contemporâneo pelo bem-estar termina por converter-se no seu oposto - o mal-estar na civilização -, título da obra de Sigmund Freud, que se deve ao sentimento de culpa que acompanha a humanidade nesse contexto histórico.

Igualmente, os dois autores citam os mesmos mecanismos para lidar com o desprazer gerado pelo modo de subjetivação característico da sociedade moderna: a fé religiosa, o entorpecimento e o trabalho. A fé religiosa se manifesta na desvalorização da vida e na exaltação de uma suposta vida após a morte num paraíso, que seria plena de satisfação, capaz de fazer com que o homem troque a busca de prazer nesta vida como forma de obter acesso àquela agindo de modo virtuoso e pelo alívio que gera em relação aos sofrimentos do indivíduo. Entretanto, a religiosidade se encontra em declínio como previa Freud (1996[1927]) devido à proliferação do conhecimento científico, um fator que influencia nesse processo de secularização, por conta das explicações racionais que a ciência pode atribuir aos fenômenos da vida.

O entorpecimento constitui um dos principais instrumentos para lidar com o desprazer, sobretudo com o avanço na farmacologia e a expansão do cultivo de drogas ilícitas. Melman (2008) aponta que o desejo humano é compatível com o desconforto que o indivíduo moderno tenta evitar ao máximo, por isso ele utiliza diversas drogas para extirpar todas as sensações e alcançar o princípio do nirvana, já que utilizar substâncias psicoativas em grandes quantidades pode ser como experimentar uma espécie de morte.

Birman (2009) acrescenta que as drogas são oferecidas em grande quantidade pela psiquiatria e outras modalidades médicas com o intuito de acalmar a desesperança que se faz presente na subjetividade do sujeito contemporâneo. Este autor sinaliza que com o desenvolvimento da psicofarmacologia e as neurociências, a maciça medicalização no Ocidente atinge níveis cruéis e, seja desta maneira ou com as drogas ilícitas oferecidas pelo narcotráfico, alimenta-se a ilusão de que a dor proveniente do desamparo humano pode ser evitada pela transformação 
química que pode ser efetuada nas suas sensações. Isso gera uma compulsão por estas substâncias psicoativas devido ao seu caráter efêmero e à dependência orgânica que pode ser gerada e ampliada de acordo com a quantidade que é utilizada.

O terceiro expediente, o trabalho, está diretamente ligado ao segundo, pois constitui uma forma bastante importante de disciplinar os corpos para a execução das tarefas propostas, seja com o uso de medicamentos psiquiátricos, como antidepressivos e ansiolíticos, ou uso de drogas ilícitas que funcionem como estimulantes do sistema nervoso, comum por parte de diversos atletas. O trabalho, chamado por Nietzsche (1998, p. 123-124, grifo do autor) de atividade maquinal, corresponde a um treinamento aplicado como forma de aliviar a existência sofredora num nível considerável, pois

A atividade maquinal e o que dela é próprio - a absoluta regularidade, a obediência pontual e impensada, o modo de vida fixado uma vez por todas, o preenchimento do tempo, uma certa permissão, mesmo educação para a "impessoalidade", para o esquecimento de si, para a "incuria sui" -: de que maneira completa e sutil o sacerdote ascético soube utilizá-la na luta com a dor!

Entretanto Birman (2009) ressalta que o desamparo é uma característica imanente à modernidade e corresponde a um sintoma da "Morte de Deus"5 - causada pelo homem moderno - anunciada por Nietzsche (2001[1882]). A "morte de Deus" corresponde à colocação do ser humano no centro do mundo, sendo que o mesmo passa a ser tomando como condição primordial e medida para todas as coisas, colocando a razão humana num lugar soberano, que era ocupado por Deus. Por esse motivo Birman (2009) afirma que a modernidade pode ser caracterizada como um período antropocêntrico e antropológico.

O desamparo do indivíduo contemporâneo pode ser compreendido como conseqüência do seu próprio projeto de sociedade e da postura adotada consigo mesmo, pois como sinaliza Nietzsche (1998) o homem moderno apresenta-se como pura híbris - exagero, desmedida e insolência - em relação à Deus - por conta da exaltação da razão, em seu lugar - e com seu próprio eu por contestar a sua própria condição humana e tentar dominar os seus instintos. Freud (1996[1930]) acrescenta que a cultura não se preocupa com a possibilidade ou não de cumprir as suas exigências, pois está baseada no equívoco de que é possível para o eu resistir às expressões psíquicas do isso - que não pode ser totalmente controlado.

Freud (1996[1930]) critica o mal-estar gerado pela civilização aos indivíduos ao demonstrar o caráter singular de cada ser, fato que é bastante desprezado pela cultura. Este autor ressalta a impossibilidade de tornar os homens iguais, oferecer um único caminho a ser seguido por todos, sobretudo pela religião cristã. $\mathrm{O}$ fundador da psicanálise adverte que

Não existe uma regra de ouro que se aplique a todos: todo homem tem de descobrir por si mesmo de que modo específico ele pode ser salvo. Todos os tipos de diferentes fatores 
operarão a fim de dirigir sua escolha. É uma questão de quanta satisfação real ele pode esperar obter do mundo externo, de até onde é levado para tornar-se independente dele e, finalmente, de quanta força sente à sua disposição para alterar o mundo, a fim de adaptá-lo a seus desejos. Nisso, a sua condição psíquica desempenhará papel decisivo, independentemente das circunstâncias externas. (FREUD, 1930, p. 91).

A grande estratégia apresentada por Nietzsche (1998) para livrar o homem do sofrimento decorrente da moral moderna é convocá-lo à transmutação de todos os ideais vigentes e promover uma inversão de todos os valores, para que possam surgir outros que exalte a sua condição, a contemple, de modo contrário ao que ocorre na contemporaneidade, em que o homem sente vergonha dos seus caracteres. Este autor sinaliza para a existência de um novo tipo de ser humano capaz de sobrepor a tudo o que está posto pela sociedade, aquele capaz de afirmar o seu próprio modo de existir no mundo e não seja um simples joguete guiado pelos ideais vigentes na cultura em que está inserido. O filósofo alemão profetiza que:

Algum dia, porém, num tempo mais forte do que esse presente murcho, inseguro de si mesmo, ele virá, o homem redentor, o homem do grande amor e do grande desprezo, o espírito criador cuja força impulsora afastará sempre de toda transcendência e toda insignificância, cuja solidão será mal compreendida pelo povo, como se fosse fuga $d a$ realidade - quando será apenas a sua imersão, absorção, penetração na realidade, para que, ao retomar à luz do dia, ele possa trazer a redenção dessa realidade: sua redenção da maldição que o ideal existente sobre ela lançou. (NIETZSCHE, 1998, p. 84, grifo do autor).

Essa redenção proposta por Nietzsche (1998) corresponderia a uma negação dos valores vigentes e a afirmação da realidade seria a expressão de tudo que há de vida no ser humano, todos os seus instintos, fato comum no homem considerado primitivo por Freud (1996) não somente no sentido cronológico, também no tocante ao juízo de valor em relação ao próprio. Por isso, as ciências humanas necessitam partilhar dos mais diversos campos do saber para apreender a existência do homem de forma ampliada para sair da condição de sacerdote ascético, acusação que Paulo César de Souza (1998a) faz ao psicanalista no posfácio de Genealogia da Moral, considerando-o um sucessor do mesmo.

Podemos supor que o sacerdote ascético se vale de um grande trunfo para lidar com o desprazer - o mecanismo de sublimação proposto por Freud (1996[1930]) - que é uma forma restrita a poucos, sendo o instrumento que lhe permite o exercício de poder na civilização. Como salienta Nietzsche (1998) todo saber coloca aquele que o detém numa condição para o exercício de poder sobre os demais, portanto, o sacerdote ascético se vale do seu saber - obtido como o direcionamento dos instintos para a realização de trabalho psíquico e intelectual - para ser um líder que exerce um poder sobre a maioria da população. 


\section{ConsideraÇões FINAIS}

Ao elaborar uma crítica aos valores vigentes na modernidade, Nietzsche (1998) alerta os psicólogos para que estes se oponham ao modo de expressão moralizado que impregna todo o juízo que se faz sobre o homem. Por isso compreendemos que é de grande valia efetuar uma problematização da práxis civilizatória para que a psicologia, na condição de ciência do homem, não cumpra a missão a qual este autor atribui à ciência - de ser a forma mais ilustre do ideal ascético.

A psicanálise constitui uma vertente da psicologia que tenta se opor a essa acusação formulada por Nietzsche (1998), pois surgiu como uma crítica da modernidade, pertencente ao modernismo - na concepção de Birman (2009) - que é decorrente do produto fundamental da modernidade, o desamparo. Freud (1996[1917]) alertou que devido à descoberta de que o dinamismo das forças instintuais e a sobredeterminação dos afetos inconscientes sobre o eu e a consciência, a psicanálise pode ser considerada a terceira ferida narcísica na humanidade, ao lado da revolução proporcionada por Nicolau Copérnico, quando este revelou que o Sol está no centro do sistema planetário e não a Terra, assim como a que foi operada por Charles Darwin ao afirmar que o homem é o produto da evolução de outros animais.

Acreditamos que tal descoberta efetuada pela psicanálise é um das mais geniais achados para propiciar um exercício da psicologia que se distancie do ideal ascético. Isso denota a impossibilidade de enquadrar os indivíduos em ideais fornecidos pela cultura e questiona a possibilidade da sustentação de princípios que constituem a modernidade, como a segurança na convivência entre os humanos, o cumprimento das normas estabelecidas pela civilização por parte de todos os indivíduos e - sobretudo - a supremacia da razão no psiquismo humano.

Como assinalou Freud (1996[1917]), a verdade do homem está no inconsciente, não na consciência racional, opondo-se ao à crença de que há um sujeito autônomo que seria capaz de agir com "boa vontade" para obedecer às leis morais que o regem mesmo que não haja um proveito pessoal ou, sobretudo, com base no "imperativo categórico" como indicava Kant (2008). Este último, considerado um dos principais idealizadores da modernidade, defende que o homem deve agir de modo que a nossa ação possa valer ao mesmo tempo como princípio de uma legislação universal, isto é, agir com os outros da mesma forma que nós queremos que os outros ajam conosco. Essa máxima corresponde ao que chamou de "imperativo categórico".

Diante de tal impossibilidade podemos voltar o questionamento que inicia este trabalho, formulado por Nietzsche (1998, p. 47), "Criar um animal que pode fazer promessas - não é esta a tarefa paradoxal que a natureza se impôs, com relação ao homem? Não é este o verdadeiro problema do homem?" Acreditamos que a psicologia tem, diante deste paradoxo constituinte da modernidade, o desafio de lidar com as contradições que a fizeram surgir. Foucault (2002) sinaliza que a psicologia contemporânea se iniciou como a análise do anormal, do patológico, do conflituoso, portanto com o objetivo de normatizar e enquadrar os indivíduos nos diversos contextos em que se dá a sua atuação. 
O desafio da psicologia está, portanto, na tentativa de sair da condição de subordinada ao ideal ascético e atingir o mais além da psicologia, perceber novamente o homem como existência no mundo e caracterizá-lo pelo estilo próprio a essa existência (BINSWANGER, 1942 apud FOUCAULT, 2002). Friedrich Nietzsche e Sigmund Freud fornecem razões suficientes para assegurar-nos do caráter paradoxal da modernidade e darmos sequência, enquanto profissionais da categoria de psicólogos, a uma crítica das condições que sejam hostis à vida humana.

Friedrich Nietzsche apresentou a sua "grande psicologia", que sustenta a necessidade de operar juntamente com diversas perspectivas, visando alcançar a compreensão mais ampla e completa quanto possível dos mais diversos aspectos e dimensões admitidos por qualquer fenômeno cultural importante (NIETZSCHE, 1992). Por isso, o autor caracterizava a sua análise da cultura como uma fisiopsicologia, compreendendo que havia um enraizamento da linguagem na fisiologia, sobretudo a gramática (GIACOIA JUNIOR, 2004), fato que pode ser evidenciado pelo emprego da última como forma de investigação sobre a origem dos valores morais, feita na sua Genealogia da moral. Além disso, Nietzsche não relega, de forma alguma, a importância da história na metodologia empregada por ele na referida obra e Foucault (2002, p. 151) está de acordo com essa perspectiva, ao afirmar que "não haveria psicologia possível senão pela análise das condições de existência do homem e pela retomada do que há de mais humano no homem, quer dizer, a sua história”.

Nesse sentido partilhamos com Foucault (2002) a expectativa de que a psicologia seja a análise da existência humana em suas estruturas fundamentais. Este trabalho constitui uma tentativa modesta de seguir a direção apontada por este autor, para que possamos ampliar o nosso olhar acerca do ser humano e sobre a prática da psicologia na condição de ciência humana. Esperamos que o mesmo sirva também como um motivador para que outros escritos possam surgir com propósitos semelhantes ou mesmo para preencher possíveis lacunas encontradas aqui.

\section{Notas}

${ }^{1}$ Nietzsche e Freud utilizam o mesmo termo no alemão em seus escritos - trieb -, que embora
seja um vocábulo de ampla dimensão designa características semelhantes, pois conforme Paulo
César de Souza na nota do tradutor 21 de Além do bem e do mal (NIETZSCHE, 1992), também
no emprego do termo feito por Nietzsche nos deparamos com um conceito que se situa "no limite
entre o somático e o psíquico" tal como o define Freud (1996[1915a]), um conceito que encontra
seu lugar somente numa "fisiopsicologia", de acordo com Nietzsche (1992). Souza (1998b)
ressalta que o termo instinto é empregado nas obras de Freud publicadas pela Editora Imago, pois
estas foram traduzidas a partir da tradução inglesa (Standard Edition) na qual o termo alemão
trieb utilizado por Freud foi traduzido como instinct e, posteriormente, para o português (Edição
Standard Brasileira) como instinto. Contudo, este autor afirma que as formulações de Jaques
Lacan e, sobretudo com a publicação do Vocabulário de Psicanálise de Laplanche e Pontalis
(2004[1967]) se realiza uma crítica por parte dos teóricos franceses à versão dada por instinto.
Assim, difundiu-se a alternativa francesa pulsion, que foi adotada em outras línguas neolatinas e
no Brasil passou a se utilizar o termo pulsão entre os psicanalistas brasileiros. Desta forma, embora
seja aplicado o termo instinto quando estivermos abordando o pensamento de Nietzsche e pulsão
quando for abordado o discurso freudiano estamos nos referindo ao termo mesmo termo - trieb -e
à mesma designação.
2Será empregado neste artigo a tradução dos termos Ich, ego e moi adotada na língua francesa no
Vocabulário de Psicanálise, de Laplanche e Pontalis (2004[1967]), que difere dos termos "id",

Fractal: Revista de Psicologia, v. 24 - n. 1, p. 59-80, Jan./Abr. 2012 
"ego" e "superego", presentes na Edição Standard Brasileira, da Editora Imago.

${ }^{3}$ Utilizamos a tradução adotada, para o francês, por LAPLANCHE, J.; PONTALIS, J. B (2004[1967]) para o termo verdrängung, traduzido na Edição Standard Brasileira como repressão.

${ }^{4}$ No artigo "A história do movimento psicanalítico" (1996[1914]) Freud afirma que evitou o prazer de ler as obras de Nietzsche, pois não queria prejudicar - com as idéias intuitivas deste autor a elaboração das impressões obtidas com a psicanálise. $\mathrm{O}$ autor alega que teve de se preparar para renunciar a pretensão de um imediatismo nas situações em que a investigação psicanalítica trabalhosa poderia confirmar as verdades que o filósofo reconheceu por intuição. Entretanto, em diversas obras, adota termos que foram utilizados por Nietzsche e faz menção a este, como no caso do emprego da palavra id. Freud (1996[1933]) assinala que aceita o termo id, empregado por Nietzsche, para expressar a principal característica da região do inconsciente dissociada do ego. Além disso, no seu escrito "Psicologia de grupo e análise do ego" (1996[1921]), Freud reconhece a equivalência entre o conceito que chamou de pai primitivo e o conceito de super-homem, desenvolvido por Nietzsche, que para ele eram equivalentes - o que demonstra que Freud conheceu parte da obra de Nietzsche. Em "Um estudo autobiográfico" (1996[1925]) Freud revela que evitou cuidadosamente um contato com a filosofia durante o último período de seu trabalho - "O ego e o id" (1996[1923]) - para que não houvesse a impressão que ele estava se entregando a especulações no seu escrito de 1925. Contudo, neste mesmo trabalho, o autor afirma ter lido Schopenhauer ainda que muito tardiamente, embora reconheça muitas coincidências entre a obra deste filósofo e a psicanálise - e aponta que os livros de Nietzsche durante muito tempo foram evitados pelo mesmo motivo, para evitar que a psicanálise seja vista como uma especulação, embora perceba que as concepções deste muitas vezes também sejam equivalentes à da psicanálise. Todavia Freud não mais assegura que não tenha lido os escritos deste último.

${ }^{5}$ Friedrich Nietzsche foi o primeiro pensador a anunciar a "Morte de Deus" pelo homem moderno. $\mathrm{O}$ autor se refere pela primeira vez a esse episódio no livro A Gaia Ciência (NIETZSCHE, 2001[1882], §108).

\section{REFERÊNCIAS}

BIRMAN, J. Arquivos do mal-estar e da resistência. Rio de Janeiro: Civilização Brasileira, 2009.

DESCARTES, R. O discurso do método. São Paulo: Martins Fontes, 2009.

ELIAS, N. O processo civilizador. Rio de Janeiro: J. Zahar, 1994.

FREUD, S. A história do movimento psicanalítico (1914). In: . Obras Psicológicas Completas de Sigmund Freud. Rio de Janeiro: Imago, 1996. v. XIV, p. 18-75. Edição Standard Brasileira.

FREUD, S. O instinto e suas vicissitudes (1915a). In: . Obras Psicológicas Completas de Sigmund Freud. Rio de Janeiro: Imago, 1996. v. XIV, p. 117-123. Edição Standard Brasileira.

FREUD, S. O Inconsciente (1915b). In: . Obras Psicológicas Completas de Sigmund Freud. Rio de Janeiro: Imago, 1996. v. XIV, p. 171-224. Edição Standard Brasileira.

FREUD, S. Uma dificuldade no caminho da psicanálise (1917). In: Obras Psicológicas Completas de Sigmund Freud. Rio de Janeiro: Imago, 1996. v. XVII, p. 145-156. Edição Standard Brasileira. 
FREUD, S. Psicologia de grupo e análise do ego (1921). In: . Obras Psicológicas Completas de Sigmund Freud. Rio de Janeiro: Imago, 1996. v. XVIII, p. 81-156. Edição Standard Brasileira.

FREUD, S. O ego e o id e outros trabalhos (1923). In: Obras Psicológicas Completas de Sigmund Freud. Rio de Janeiro: Imago, 1996. v. XIX, p. 25-82. Edição Standard Brasileira.

FREUD, S. Um estudo autobiográfico (1925). In: . Obras Psicológicas Completas de Sigmund Freud. Rio de Janeiro: Imago, 1996. v. XX, p. 17-94. Edição Standard Brasileira.

FREUD, S. O futuro de uma ilusão (1927). - Obras Psicológicas Completas de Sigmund Freud. Rio de Janeiro: Imago, 1996. v. XXI, p. 15-44. Edição Standard Brasileira.

FREUD, S. O Mal-estar na Civilização (1930). In: . Obras Psicológicas Completas de Sigmund Freud. Rio de Janeiro: Imago, 1996. v. XXI, p. 73-150. Edição Standard Brasileira.

FREUD, S. Conferência XXXI: A dissecção da personalidade psíquica (1933). In: . Obras Psicológicas Completas de Sigmund Freud. Rio de Janeiro: Imago, 1996. , v. XXII, p. 63-84. Edição Standard Brasileira.

FOUCAULT, M. A verdade e as formas jurídicas. 3. ed. Rio de Janeiro: Nau, 2005.

FOUCAULT, M. A psicologia de 1850 a 1950. In: . Problematização do sujeito: psicologia, psiquiatria e psicanálise. 2. Ed. Rio de Janeiro: Forense universitária, 2002. p. 133-151.

GIACOIA JUNIOR, O. Introdução. In: São Leopoldo-RS: Unisinos, 2004. p. 7-14. . Nietzsche como Psicólogo. 2. ed.

GIACOIA JUNIOR, O. Pequeno dicionário de filosofia contemporânea. São Paulo: Publifolha, 2006.

KANT, I. Crítica da razão prática. São Paulo: Martins Fontes, 2008.

LAPLANCHE, J.; PONTALIS, J. B. Vocabulário da psicanálise (1967). 4. ed. São Paulo: Martins Fontes, 2004.

MELMAN, C. O homem sem gravidade: gozar a qualquer preço. Rio de Janeiro: Companhia de Freud, 2008. 
NAFFAH NETO, A. O elogio ao mundo trágico. In: Nietzsche: a vida como valor maior. São Paulo: FTD, 1996. p. 36-51.

NAFFAH NETO, A. Nietzsche e a Psicanálise. Cadernos Nietzsche, São Paulo, n. 2, p. 41-53, 1997. Disponível em: <http://www.fflch.usp.br/df/gen/cn/cn_02. html . Acesso em: 21 ago. 2009.

NIETZSCHE, F. Dos preconceitos dos filósofos. In: mal. São Paulo: Cia. das Letras, 1992. p. 9-28. . Além do bem e do

NIETZSCHE, F. Genealogia da moral: uma polêmica. São Paulo: Cia das Letras, 1998.

NIETZSCHE, F. A gaia ciência (1882). São Paulo: Cia das Letras, 2001.

SOUZA, P. C. Posfácio. In: Genealogia da moral: uma polêmica. São Paulo: Cia das Letras, 1998a. p. 169-172.

SOUZA, P. C. As palavras de Freud. São Paulo: Editora Ática, 1998b.

Recebido em: 04 de abril de 2010 Aceito em: 01 de fevereiro de 2012 